\title{
UTILIZATION OF BAGASSE AND BY-PASS CEMENT IN PRODUCTION OF BRICKS
}

\section{Moussa A. M. ${ }^{1}$ and El- Bialee N. M. ${ }^{2}$}

\begin{abstract}
The aim of this research was manufacturing bricks has good specifications and environment friendly as well benefit of agricultural wastes in production of bricks. The mixtures were content of: (1) different ratios of bagasse "SB" (5, 10, and 15\%) with cement kiln dust "CKD", bypass cement, (45, 40, and 35\%), (2) constant ratios of cement "OPC" (21\%), sand "S" (15\%), fly ash "FA" (9\%) and hydrated lime "HL" (5\%) by weight. Fifty four pieces of bricks were manufacture, prepared on 6 sample groups, with 9 bricks in each group. Each 27 bricks were using different particle size: (1) small chops "SC" ( $\leq 2.8 \mathrm{~mm})$ and (2) large chops "LC" (> $2.8 \mathrm{~mm}$ ) with various dosages of $S B$ contents ranging from 5, 10 and $15 \%$ were added. Samples were manually mixed and placed into pressing mold to completion pressure. Then, samples were leaved to dry in the air for 28 days. Some physical and mechanical properties were measurement for these bricks. The obtained data showed that acoustic insulation and expansion increase with increasing $S B$ in mixture while bulk density decrease for both SC and LC. The maximum value of bulk density was $1.43 \mathrm{~g} / \mathrm{cm}^{3}$ at ratio of $5 \%$ SB for $S C$, the minimum value was $1.17 \mathrm{~g} / \mathrm{cm}^{3}$ at ratio of $15 \% \mathrm{SB}$ for $L C$. The maximum value of expansion was $10.46 \%$ at ratio of $15 \%$ SB for LC; the minimum value was $1.99 \%$ at ratio of 5\% SB for SC. Water absorption percentage decreases with increasing $S B$ for $S C$ and increases with increasing $S B$ for $L C$. The maximum value of water absorption percentage was $29.09 \%$ at ratio of $10 \%$ SB for $L C$; the minimum value was $18.99 \%$ at ratio of $5 \%$ SB for $L C$. Ratio of $15 \%$ SB for SC was gave higher compression stresses " $\delta_{c}$ " $\left(\mathrm{kN} / \mathrm{cm}^{2}\right)$ at lower strains. The values of compression stresses " $\delta_{c}$ " at $15 \%$ $S B$ for SC were $0.18,0.48$ and $1.03 \mathrm{kN} / \mathrm{cm}^{2}$ at strains of $0.102,0.154$ and 0.2 , respectively.
\end{abstract}

1- Lect. of Water System. and Irr. Eng. Dept., Fac. of Ag. Eng., AL-Azhar Univ. Cairo.

2- Researcher. Ag. Eng. Res. Inst. (AEnRI), Giza. 
Bending momentum increases with increasing SB for both SC and LC. The maximum value of bending momentum was $93.75 \mathrm{KN} . \mathrm{mm}$ at ratio of $15 \% \mathrm{SB}$ for $\mathrm{SC}$; the minimum value was $62.5 \mathrm{KN} . \mathrm{mm}$ at ratio of $5 \% \mathrm{SB}$ for LC.

\section{1- INTRODUCTION}

Bagasse is residue that remains after sugarcane stalks are crushed to extract their juice. It is used as a biofuel, in the manufacture of pulp and building materials. Aggarwal (1995) found that bulk density decreases with creasing bagasse percentage in the bagasse - cement mix while the water absorption percentage increase. Also, the bagasse-cement has good resistance to moisture and should be durable in service. Cement kiln dust is a by-product generated during the production of Portland cement. As, the raw materials are heated in the kiln, dust particles are produced and then carried out with the exhaust gases at the upper end of the kiln. This dust is harmful on the health of human and causes environmental problems. Also, the transport and disposal of this dust is high-cost. Singh et al. (2000) mentioned that addition of 5 to 10 percent from by-pass dust in the Portland cement decreased the water requirements, accelerated the hydration, decreased the porosity and increased the compressive strengths at all ages of hydration. Replaced the gypsum by cement dust in the manufacture of agro-gypsum panels from corn stalks lead to big improvements in the physical and mechanical properties (Basta et al. 2004). Momamed et al. (2014) studied of influence polypropylene fiber (PPF) on stress strain characteristics for concrete containing cement-kilndust (CKD) as well as fresh and mechanical properties. The results indicated that (PPF) and (CKD) could be successfully used in concrete production. Algin and Turgut (2008) investigated that replacement of cotton wastes with limestone powder wastes in concrete bricks mixes gave a sturdy lighter weight composite. Muska et al. (2018) Developed of unfired earth bricks by addition fly ash (F), lime (L), wood aggregates (W) for all mixtures. The mechanical strength, water absorption and costs determined and compared to $10 \%$ cement stabilized unfired earth bricks. Dry compressive strength was significantly higher with (L 10\% - F 10\% -w $1.5 \%$ ) ratios than $10 \%$ cement stabilized unfired earth bricks. 
The aim of this research manufacturing bricks has good specifications and environment friendly as well benefit of agricultural wastes in production of bricks. Also, study of the physical and mechanical properties of these bricks.

\section{2- MATERIALS AND METHODS}

The experiment was carried out at the workshop of Fac. of Agric. Eng., Al-Azhar Univ., Cairo, Egypt. Six different types of mixtures were prepared by varying the ratios bagasse with cement kiln dust. Samples were manually mixed and placed into pressing mold to completion pressure. Then, samples were leaved to dry in the air for 28 days.

\subsection{Materials:}

The base materials for the specimen bricks manufacturing are made from a mixture of locally cement, sand, hydrated lime, and wastes i.e., bypass, sugar cane bagasse, and fly ash.

Cement is a main binding material. Ordinary Portland Cement "OPC", type "CEM I" - 42.5 N Grade - with commercial name of "Tourah", is used. It is manufactured as described in Egypt Standards "ES 4756 - 2013" that complies with the "EN 197 -1 -2000", which it satisfied the quality requirements of ASTM C 150-2000.

Fine mine sand "S", spherical and clean (liberate from clay, loam, dirt and any organic or chemical matter), was well graded. The sand passed through a sieve of $2 \mathrm{~mm}$, liquid limit $\leq 45 \%$ and plasticity index $\leq$ $18 \%$, with bulk density $\approx 1.64 \mathrm{gcm}^{-3}$. While, the moisture content recorded was $2.36 \%$. Consequently, it is deemed suitable for bricks production. It was complying with the requirements of ASTM C 778-2000.

Hydrate lime "HL" available in the market was used for block manufacturing work, which it satisfied the quality requirements of ASTM C 911-1999.

Bypass or cement kiln dust "CKD" is a fine powder-like material made up of particles that are relatively uniform in size. The chemical composition of CKD depends on the raw materials used to produce the clinker and on the type and source of the carbon-based fuel used to heat the material in the rotary kiln.

Sugarcane bagasse "SB" is the cellular fibrous waste product after the sugar juice extraction. It acquired from different sugar mill with about 
48-50\% moisture content "MC". Then, spread on the floor to sun dried for two weeks, to solidify the bagasse, till a final humidity of 5\% (wet basis). Posterior, "SB" grinded to powder by hammer mill machine and sieved to divide into two sizes; small chops "SC" ( $\leq 2.8 \mathrm{~mm})$, and large chops "LC" (> $2.8 \mathrm{~mm}$ ), which used in the current experiment. It contains approximately $52.62 \%$, cellulose, 25.8 , hemi-cellulose, $20.23 \%$, lignin, and 1.35 , ash. Chemical composition determined according previously described by Claye et al., 1996.

Fly ash "FA" is the finely divided residue that results from the combustion of pulverized coal and is transported from the combustion chamber by exhaust gases. It was passed through a sieve of $2 \mathrm{~mm}$ to use in mixture. The chemical composition of OPC, S, HL, CKD and FA were investigated in Housing and Building National Research Center (HBNRC) and tabulated here in Table 1.

Table 1: Chemical compositions of raw materials.

\begin{tabular}{|c|c|c|c|c|c|}
\hline Oxides & $\begin{array}{c}\text { Cement } \\
\text { "OPC" \% }\end{array}$ & $\begin{array}{c}\text { Sand } \\
\text { "S" \% }\end{array}$ & $\begin{array}{c}\text { Hydrate lime } \\
\text { "HL" \% }\end{array}$ & $\begin{array}{c}\text { Cement kiln dust } \\
\text { "CKD" \% }\end{array}$ & $\begin{array}{c}\text { Fly ash } \\
\text { "FA" \% }\end{array}$ \\
\hline $\mathrm{SiO}_{2}$ & 20.29 & 93.32 & 2.88 & 13.75 & 55 \\
\hline $\mathrm{Al}_{2} \mathrm{O}_{3}$ & 5.40 & 0.51 & 5.4 & 3.8 & 26 \\
\hline $\mathrm{Fe}_{2} \mathrm{O}_{3}$ & 2.66 & 0.84 & 0.25 & 2.16 & 7 \\
\hline $\mathrm{CaO}$ & 64.17 & 0.49 & 62.58 & 49.8 & 9 \\
\hline $\mathrm{MgO}$ & 1.5 & 1.62 & 1.006 & 1.7 & 2 \\
\hline $\mathrm{Na}_{2} \mathrm{O}$ & 0.47 & 0.09 & 0.6 & 1.59 & - \\
\hline $\mathrm{K}_{2} \mathrm{O}$ & 0.12 & 0.87 & 0.12 & 2.75 & - \\
\hline $\mathrm{P}_{2} \mathrm{O}_{5}$ & 0.05 & 0.05 & 0.01 & - & - \\
\hline $\mathrm{SO}_{3}$ & 2.93 & 0.03 & 0.534 & 1.85 & 1 \\
\hline $\mathrm{IR}$ & 1.05 & - & - & 1.5 & - \\
\hline $\mathrm{LOI}$ & 1.36 & 2.18 & 26.62 & 21.1 & - \\
\hline \multicolumn{7}{|c}{ * IR: Insoluble residues } & * LOI: Losses on Ignition \\
\hline
\end{tabular}

Water used to mix the materials. It activates the chemical reaction in the cement and with other materials and forms cement gel. Fresh, colorless, odorless, tasteless, free of acids, organic matter, suspended solids, alkalis and impurities with PH value of 7.0 confirming to "IS 4562000", was used for curing specimen. It was collected from the pipe borne 
water of Holding Company for Water and Wastewater "HCWW". The chemical composition of water was analyzed in central lab. of Soil, Water and Environment Research Institute "SWERI" and recorded in table 2.

Table 2: Chemical compositions of water

\begin{tabular}{|c|c|c|c|c|}
\hline $\begin{array}{c}\text { Clorides }\left(\mathrm{Cl}^{-}\right) \\
\text {"ppm" }\end{array}$ & \multicolumn{2}{|c|}{$\begin{array}{c}\text { Sulphates } \\
\text { "ppm" }\end{array}$} & $\begin{array}{c}\text { Total dissolved salts } \\
\text { (TDS) "ppm" }\end{array}$ & $\begin{array}{c}\mathrm{Na}_{2} \mathrm{O}+0.658 \mathrm{~K}_{2} \mathrm{O} \\
\text { "ppm" }\end{array}$ \\
\cline { 2 - 3 } & $\left(\mathrm{SO}_{3}\right)$ & $\left(\mathrm{SO}_{4}\right)$ & & \\
\hline 12.5 & 62 & 23 & 521.7 & 25.9 \\
\hline
\end{tabular}

\subsection{Mixing and fabrication of bricks:}

Brick specimen preparation processes include mixing and pressing. The quantities of the materials for each specimen about $2000 \mathrm{~g}$. were batched by weight. Half $(50 \%)$ of the overall quantities for constituents were constant rates, such as OPC, S, HL and FA, were 420, 300, 100, $180 \mathrm{~g}$. respectively. As well as, SB with particle sizes (SC and LC) varied from $5,10,15 \%$ in other $50 \%$ of quantities and the rest of CKD.

OPC, $\mathrm{S}$ and HL were mixed beforehand in Lab., before they were mixed with FA and CKD. Later, it mixed with SB manually, on piece of plywood, with adding water $(550 \mathrm{ml})$ to prepare the wet mixture. The mixing process takes $20 \mathrm{~min}$., approx., for each specimen to achieve the homogeneity and to ensure an even dispersion of all the matrix and SB.

After mixing, the materials were molded to brick by filled rectangular mold size $250 \times 120 \times 100 \mathrm{~mm}$. Then, pressing apparatus (calibrated hydraulic cylinder) used to press out the mixtures, with formation pressure about $45.98 \mathrm{Kg} / \mathrm{cm}^{2}$ for $30 \mathrm{~min}$. The block diagram below (Fig. 1) illustrates the methodology followed in the manufacturing of brick specimens containing wastes.

Fifty four pieces of bricks were manufacture, prepared on six sample groups, with nine bricks in each group. Each twenty seven bricks were using different particle size (SC or LC); with various dosages of SB contents ranging from 5, 10 and $15 \%$ were added.

Later than, brick specimens placed on timber palettes and were leaved to dry in air for 28 days prior to use in the sequence of laboratory tests.

Generally, bricks are hardened from a chemical reaction and from mechanical compaction. Chemical reactions occur when the added OPC reacts with other components. When compacted by mechanical force, all 
components are bonded tightly, decreasing the porosity of the bricks and increasing their density.

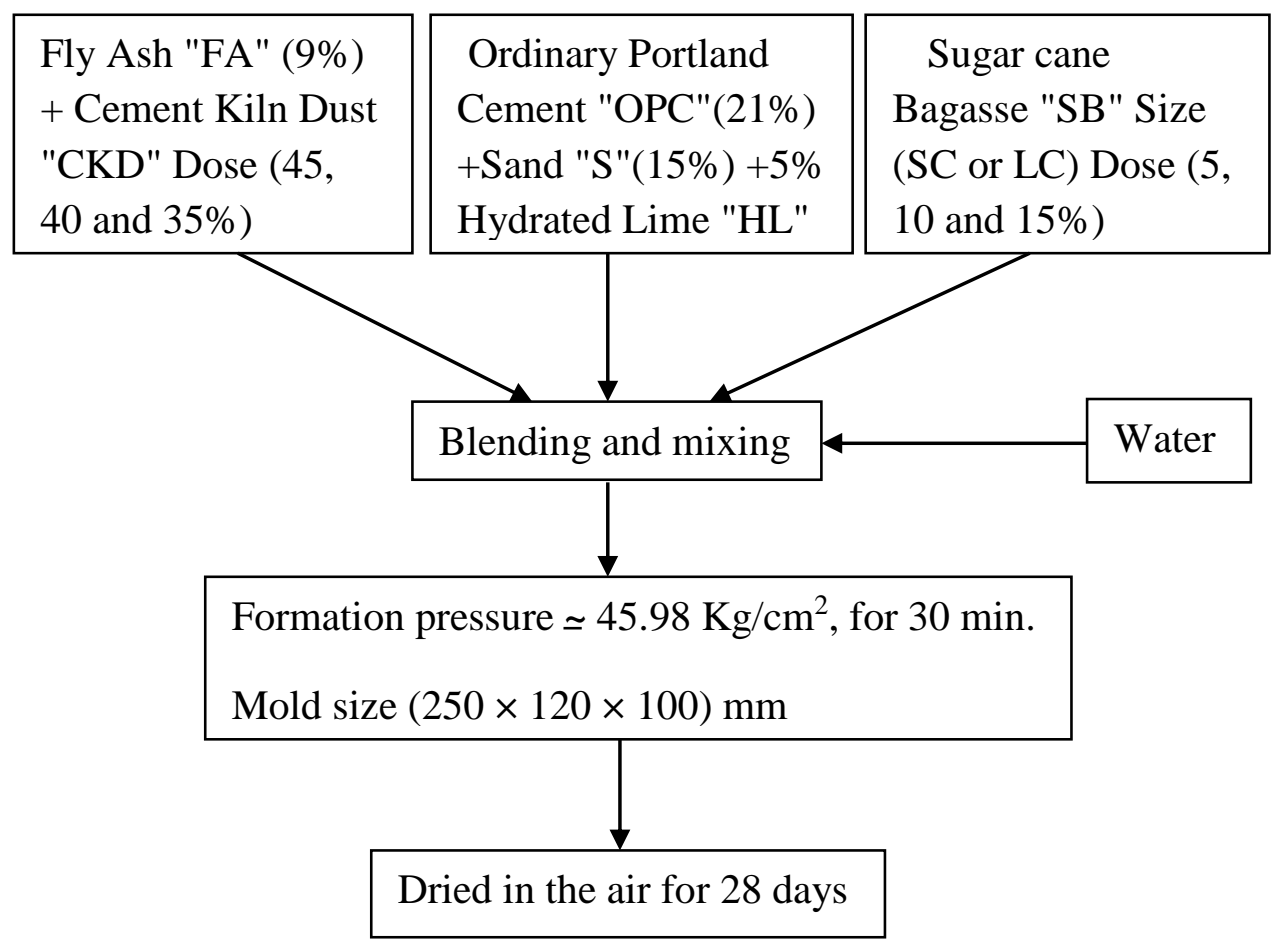

Fig. 1: Eco-friendly brick (specimen) manufacturing methodology.

\subsection{Test methods:}

A serious measurements were conducted to determine physic-mechanical and functional brick properties i.e., bulk density " $\rho "\left(\mathrm{~g} \mathrm{~cm}^{-3}\right)$, expansion "E" (\%), acoustic insulation "Ai" (\%), water absorption "Wa" (\%), compression stress-strain " $\delta_{\mathrm{c}^{-}} \varepsilon$ " and bending momentum " $\mathrm{M}_{\mathrm{b}}$ ", were executed after cured bricks for 28 days at room temperature.

\subsubsection{Bulk density:}

The average of five randomly bricks samples dimensions (length "1", width "w" and thickness "t") were measured by digital vernier caliper with an accuracy of $0.01 \mathrm{~mm}$ and mass was recorded. Then, there were established in following formula to obtain $\rho$ as ASTM C 642-97 and C 67-2001.

$$
\rho=\frac{M}{\mathrm{~V}}
$$

Where: $\mathrm{M}=$ sample mass, $\mathrm{kg}$., and $\mathrm{V}=$ sample volume $=1 \times \mathrm{w} \times \mathrm{t}, \mathrm{cm}^{3}$. 


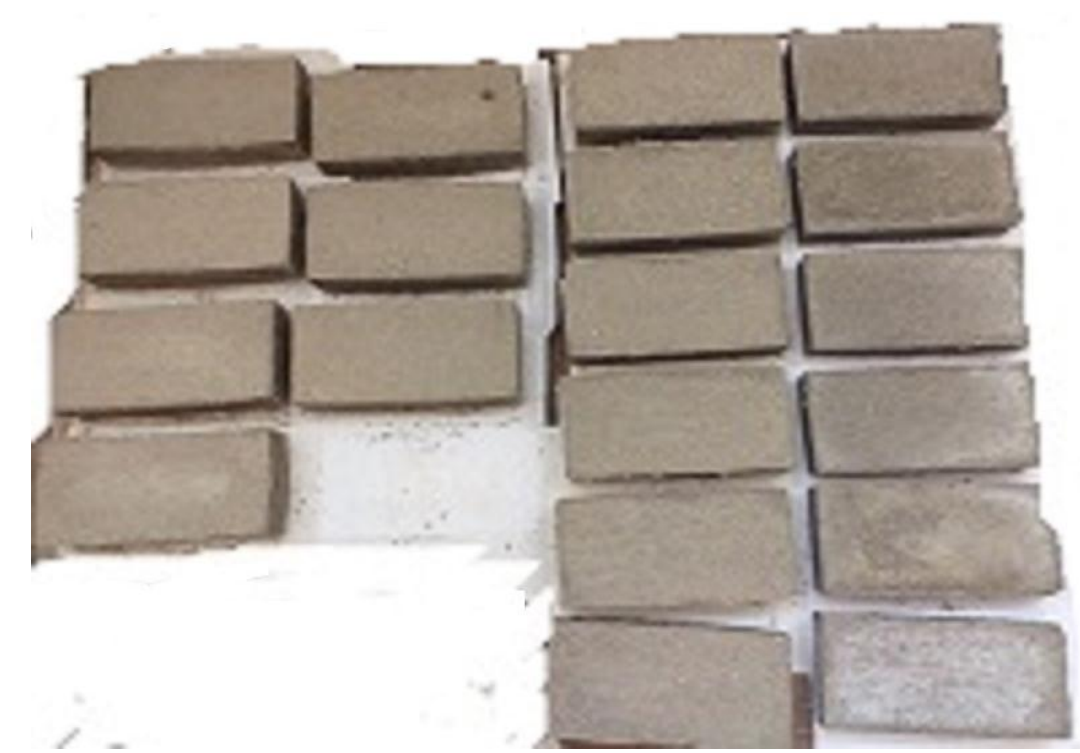

Fig. 2: Some of bricks manufacturing from the bagasse different ratios with cement kiln dust.

\subsection{2: Expansion:}

All specimens in the present study expanded, this is because adding the bagasse. Thickness of specimens was measured when they were wetted and after dried it, and expansion percentage was calculated as follows as described ASTM C 1038-1995:

$$
E=\frac{t_{d}-t_{w}}{t_{w}} \times 100
$$

Where:

$t_{d}=$ Thickness of dry sample, mm., $\mathrm{t}_{\mathrm{w}}=$ Thickness of wet sample, $\mathrm{mm}$.

\subsubsection{Acoustic insulation:}

Digital sound level meter, range 50 to $126 \mathrm{~dB}$ with $+2 \mathrm{~dB}$ accuracy, used to measure acoustic insulation percentage "Ai" (\%) as described by Mousa, 2008.

\subsubsection{Water absorption:}

The brick samples were immersion in water on a narrow wiry mesh for 24 $\mathrm{h}$ after the initial mass for specimen was recorded. Then, samples and a narrow wiry mesh were withdrawn from water and the excess water was strained and was weighed again. The water absorption percentage (Wa) was calculated as follows: 


$$
\mathrm{Wa}=\frac{\mathrm{M}_{\mathrm{w}}-\mathrm{M}_{\mathrm{d}}}{\mathrm{M}_{\mathrm{d}}} \times 100
$$

Where:

$\mathrm{M}_{\mathrm{W}}=$ Mass of wet sample ( $\mathrm{g}$ ),

$\mathrm{M}_{\mathrm{d}}=$ Initial mass of sample $(\mathrm{g})$.

\subsubsection{Compression stress-strain:}

The used of fibers in concrete lead to shrinkage of mixing at pressing and expansion at dried it. Therefore, an investigation was performed to examine the effect of bagasse on stress-strain characteristics by testing of samples under the digital hydraulic universal testing machine UTM, of the Construction Research Institute, CRI, Egypt (Fig. 3), which has a LVDT transducer for measuring the vertical induced displacement in addition to the applied load reading, maximum reading $500 \mathrm{kN}$ with 0.01 $\mathrm{kN}$ accuracy. Compression stress " $\delta_{\mathrm{c}}$ " was calculated as follows:

$$
\delta_{\mathrm{c}}=\frac{\mathrm{P}}{\mathrm{A}}, \mathrm{kN} / \mathrm{cm}^{2}
$$

Where:

$\mathrm{P}=$ Load, $\mathrm{kN}$,

$\mathrm{A}=$ Specimen surface area, $\mathrm{cm}^{2}$.

Strain " $\varepsilon$ " was calculated as follows:

Where:

$$
\varepsilon=\frac{D}{t_{d}}
$$

$\mathrm{D}=$ displacement, $\mathrm{mm}$.

$\mathrm{t}_{\mathrm{d}}=$ Initial thickness of dry sample, $\mathrm{mm}$.

\subsubsection{Bending momentum:}

The bending momentum was determined on previously mentioned machine by placed of the sample above two constant supports at ends, and then the load was applied onto the face of the sample at the middle. The bending momentum was calculated as follows:

$$
\mathrm{M}_{\mathrm{b}}=\frac{\mathrm{Fl}}{4}
$$

Where:

$\mathrm{F}=$ force, $\mathrm{kN}$.

$1=$ the length between two supports, $\mathrm{mm}$. 


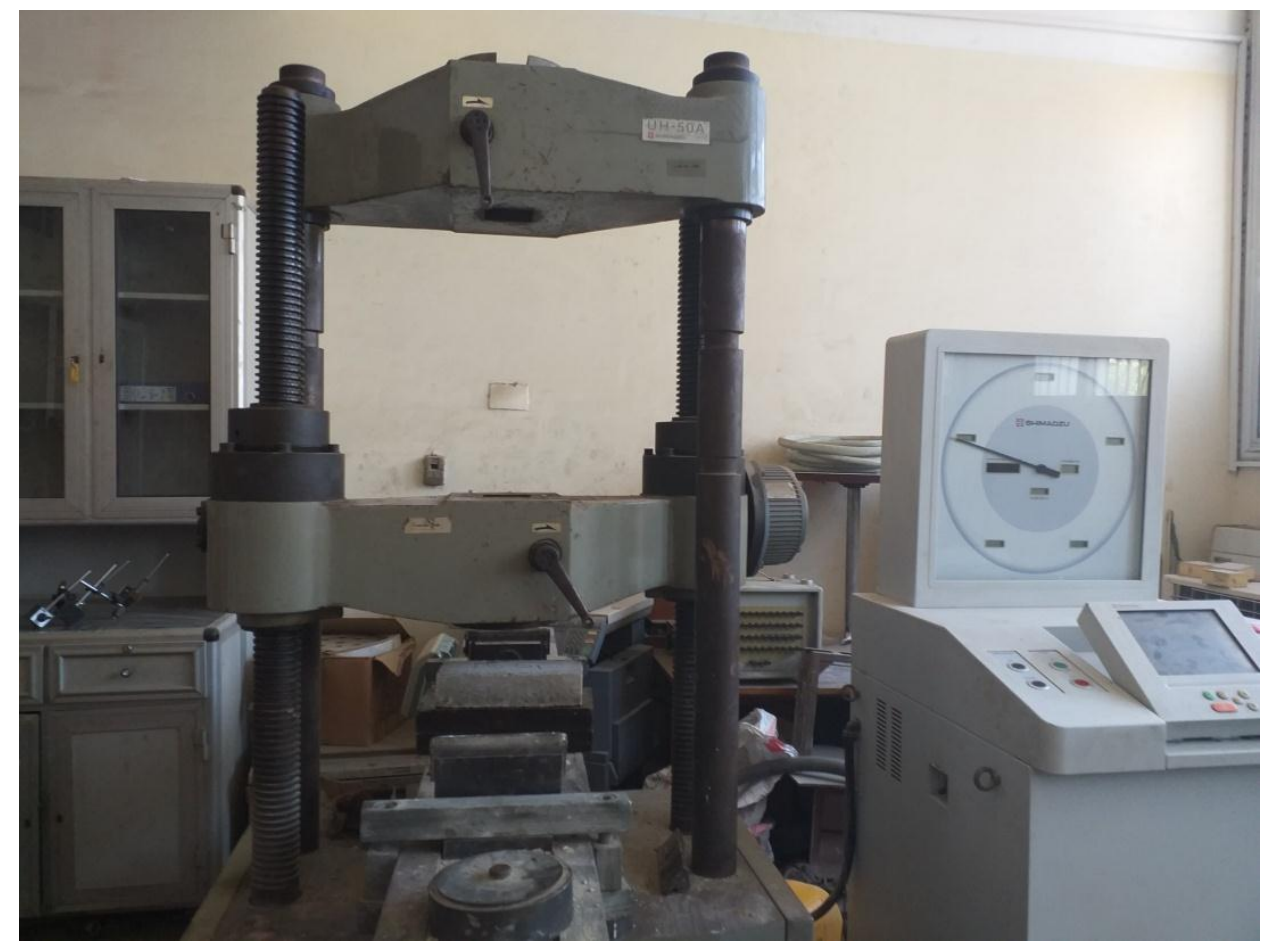

Fig. 3: Testing machine used for measuring compressive stress-strain and bending momentum.

\section{RESULTS AND DISCUSSION}

\subsection{Bulk density, acoustic insulation and expansion:}

Figs 4, 5 and 6 show the relationship of bulk density " $\rho$ ", acoustic insulation "Ai" and expansion "E" with different ratios from bagasse "SB" for small chops "SC" and large chops "LC". Results indicated that acoustic insulation and expansion increase with increasing SB in mixture while bulk density decrease for both SC and LC. These results may be attributed to bagasse weight lighter material resulted in an increase in total volume of the mix which decreases bulk density.

Also, when compacted by mechanical force, all components are bonded tightly, decreasing the porosity which increases acoustic insulation. Since, bagasse has high elasticity therefore, expansion increased after dried of samples. The values of expansion were higher at LC than SC; this is may be due to SC can compact easy more than LC with other composites and have lowered porous. 


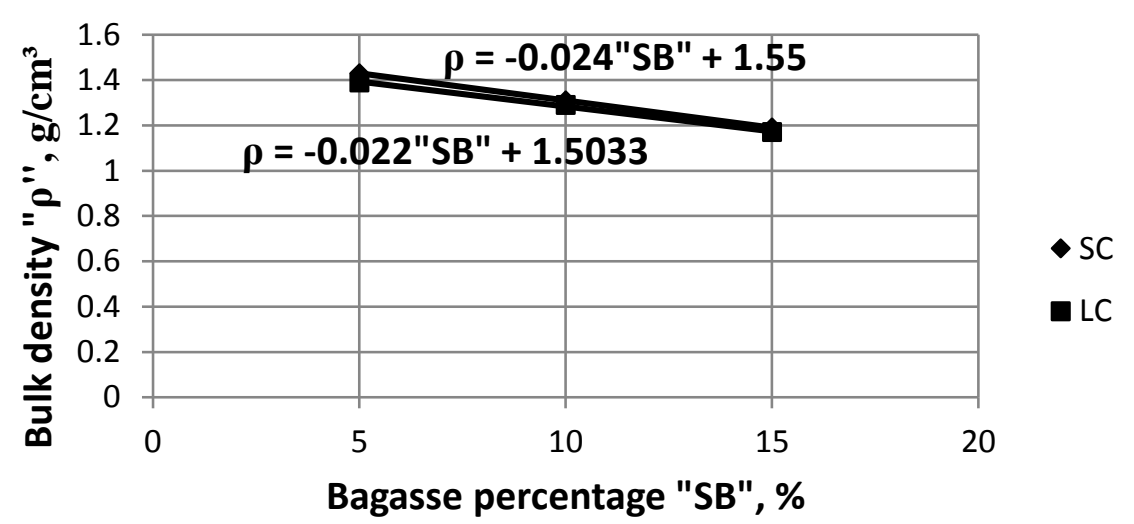

Fig. 4: Relationship between bulk density " $\rho "\left(\mathrm{~g} / \mathrm{cm}^{3}\right)$ and bagasse percentage "SB" (\%) for SC and LC.

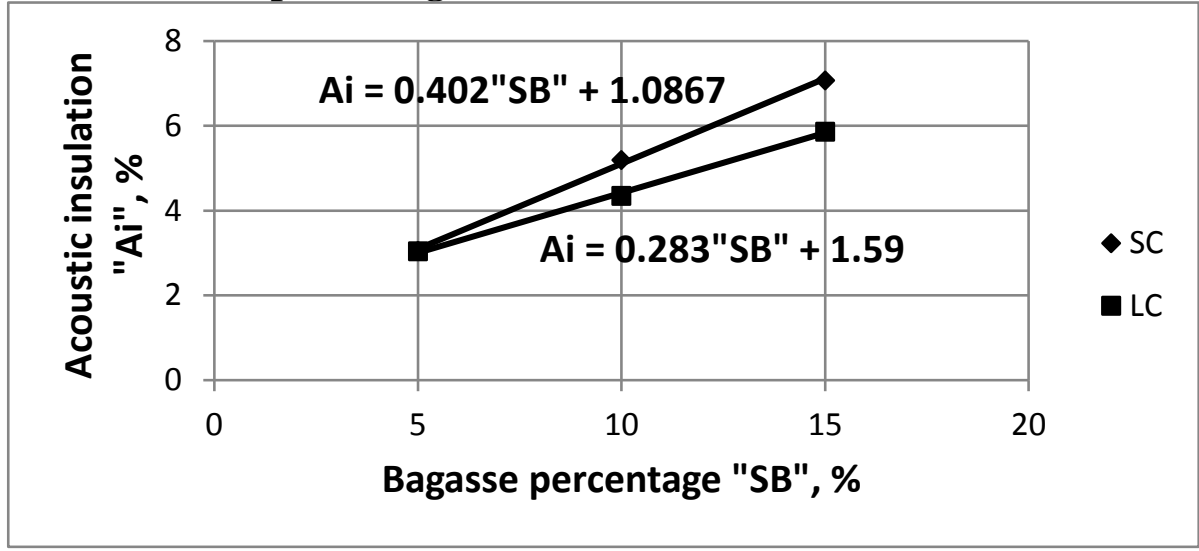

Fig. 5: Relationship between coustic insulation "Ai" (\%) and bagasse percentage "SB" (\%) for SC and LC.

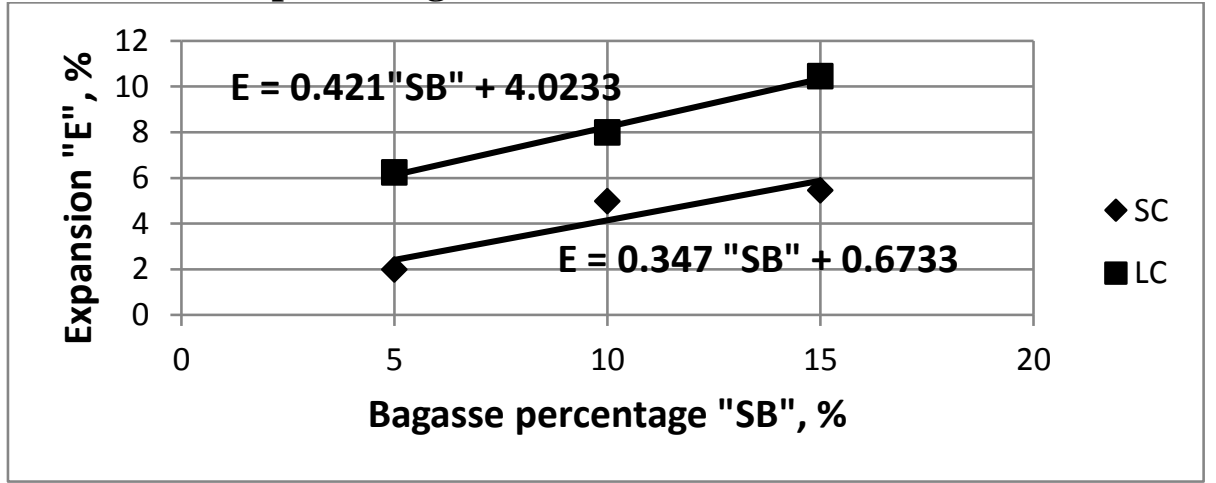

Fig. 6: Relationship between expansion "E" (\%) and bagasse percentage "SB" (\%) for SC and LC. 
The maximum value of expansion was $10.46 \%$ at ratio of $15 \%$ "SB" for $\mathrm{LC}$; the minimum value was $1.99 \%$ at ratio of $5 \%$ "SB" for SC. In figs 4 and 5 were observed that differences between SC and LC insignificant and very nearby slopes, therefore the averages of equations constant were calculated and collected in one equation for both SC and LC as follows:

$$
\begin{aligned}
& \rho=-0.023 \mathrm{SB}+1.53 \\
& \mathrm{Ai}=0.34 \mathrm{SB}+1.34
\end{aligned}
$$

So, figs 7 and 8 show the predicted and observed for bulk density " $\rho$ " and acoustic insulation "Ai" with SC and LC.

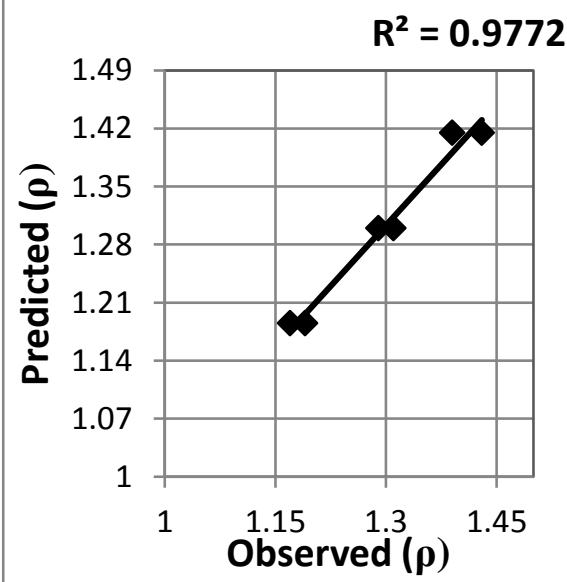

Fig. 7: Predicted and observed ( $\rho)$ for Sc and LC.

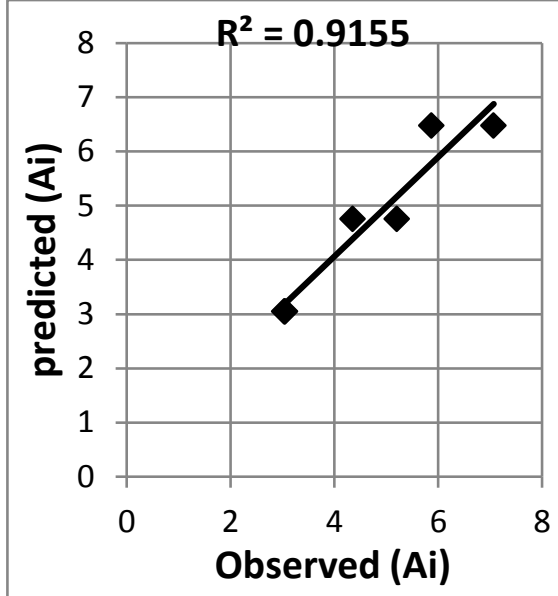

Fig. 8: Predicted and observed (Ai) for SC and LC.

\subsection{Water absorption:}

Fig. 9 shows the relationship between water absorption "Wa", (\%) and bagass percentage "SB", (\%) for two sizes of bagasse (SC and LC). Results showed that water absorption percentage decreases with increasing "SB" at SC and increases with increasing SB at $\mathrm{LC}$ but a ratio of $15 \%$ lesser than $10 \%$ SB. This is may be due to cement kiln dust has very fine particles, specific surface area is very high, therefore, it absorbed most water. Also, the formation pressure results more compacted composites, thereby decreasing the void volumes within the samples. But with LC results lower compacted composites, thereby increasing the void volumes within the samples. The decrease in water absorption at $15 \%$ SB for LC may be due to the increasing of bond to 
matrix at this the ratio. The bonding can be affected by dimensions, surface conditions and number of fibers present in a given volume of material (Zhu. et al. 1994). The maximum value of water absorption percentage was $29.09 \%$ at ratio of $10 \%$ SB for LC; the minimum value was $18.99 \%$ at ratio of $5 \% \mathrm{SB}$ for LC.

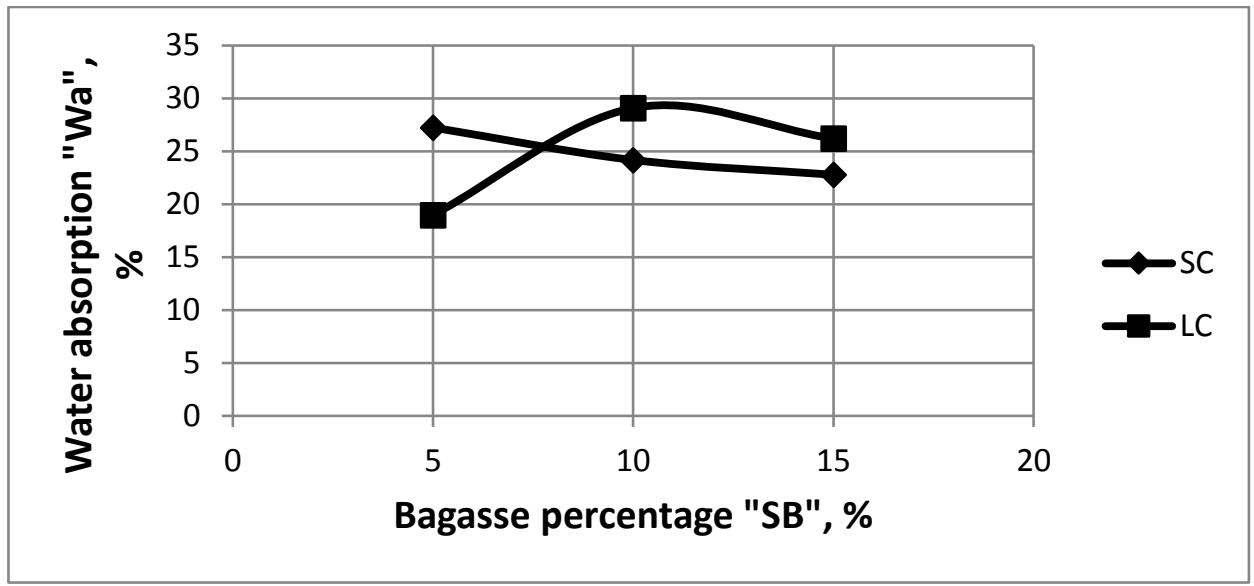

Fig. 9: Relation between water absorption "Wa" (\%) and bagasse percentage "SB" (\%) for SC and LC.

\subsection{Compression stress-strain:}

Figs 10 and 11 show compression stress-strain curves for brick specimens at different ratios of SB for SC and LC. The specimens reached to peak load $(500 \mathrm{KN})$ without cracks or crushing, thereby the curves were drawn until 0.2 strains. Results showed that $15 \%$ SB for SC was gave higher compression stresses " $\delta_{\mathrm{c}} "\left(\mathrm{kN} / \mathrm{cm}^{2}\right)$ at lower strains follow it 5\% SB for SC and LC. The values of " $\delta_{c}$ " at $15 \%$ SB for SC were $0.18,0.48$ and $1.03 \mathrm{kN} / \mathrm{cm}^{2}$ for $0.102,0.154$ and 0.2 strains, respectively; the values of " $\delta_{\mathrm{c}} "$ at $5 \%$ SB for SC were $0.05,0.20$ and $0.76 \mathrm{kN} / \mathrm{cm}^{2}$ for $0.104,0.149$ and 0.2 strains, and the values of " $\delta_{c}$ " at $5 \%$ SB for LC were $0.04,0.17$ and $0.74 \mathrm{kN} / \mathrm{cm}^{2}$ for $0.101,0.148$ and 0.2 strains, respectively. Previous ratios curves seem to have a more linear in the ascending portion of the curve that indicating a higher stiffness.

\subsection{Bending momentum:}

Fig. 12 show the relationship between bending momentum " $\mathrm{M}_{\mathrm{b}}$ " (KN.mm) and bagass percentage "SB", (\%) for two sizes of bagasse (SC and LC). Results showed that bending momentum increases with increasing SB for both SC and LC but a ratio of $15 \%$ lesser than $10 \% \mathrm{SB}$ 
for LC. This is may be due to the increasing of bond to matrix at this the ratio. The maximum value of bending momentum was $93.75 \mathrm{KN} . \mathrm{mm}$ at ratio of $15 \% \mathrm{SB}$ for $\mathrm{SC}$; the minimum value was $62.5 \mathrm{KN}$.mm at ratio of $5 \% \mathrm{SB}$ for LC.

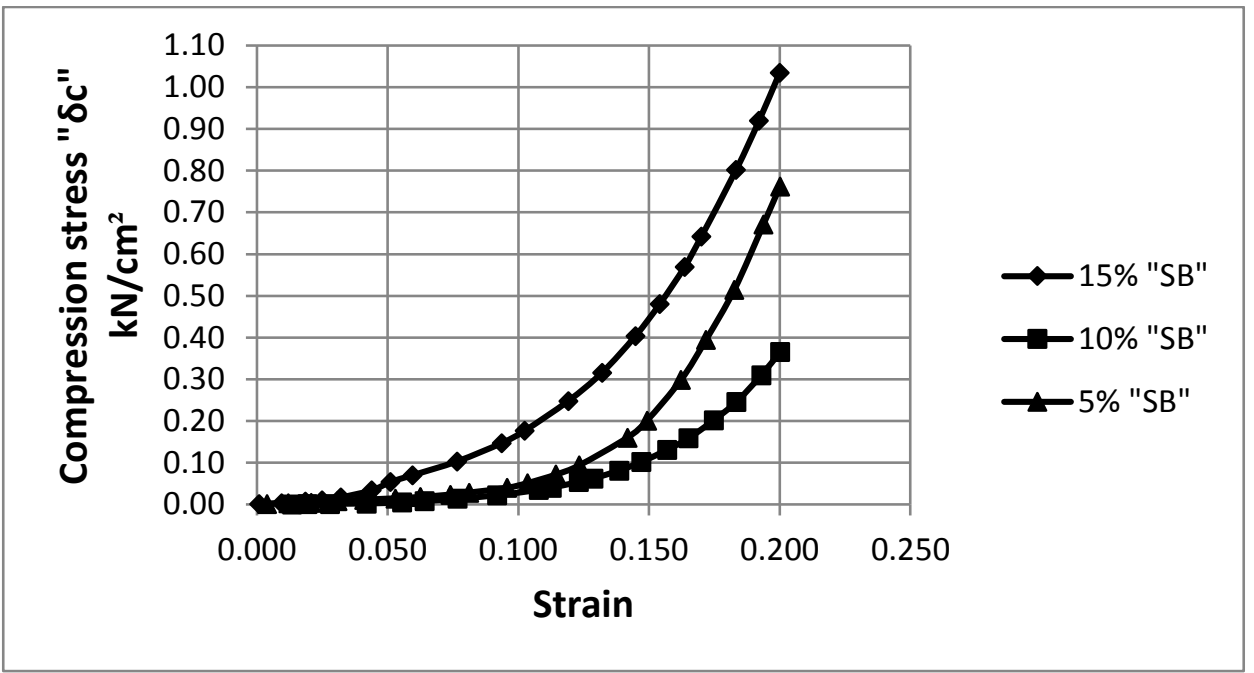

Fig. 10: Compression stress-strain curves of different bagasse percentage "SB" (\%) for small chops "SC".

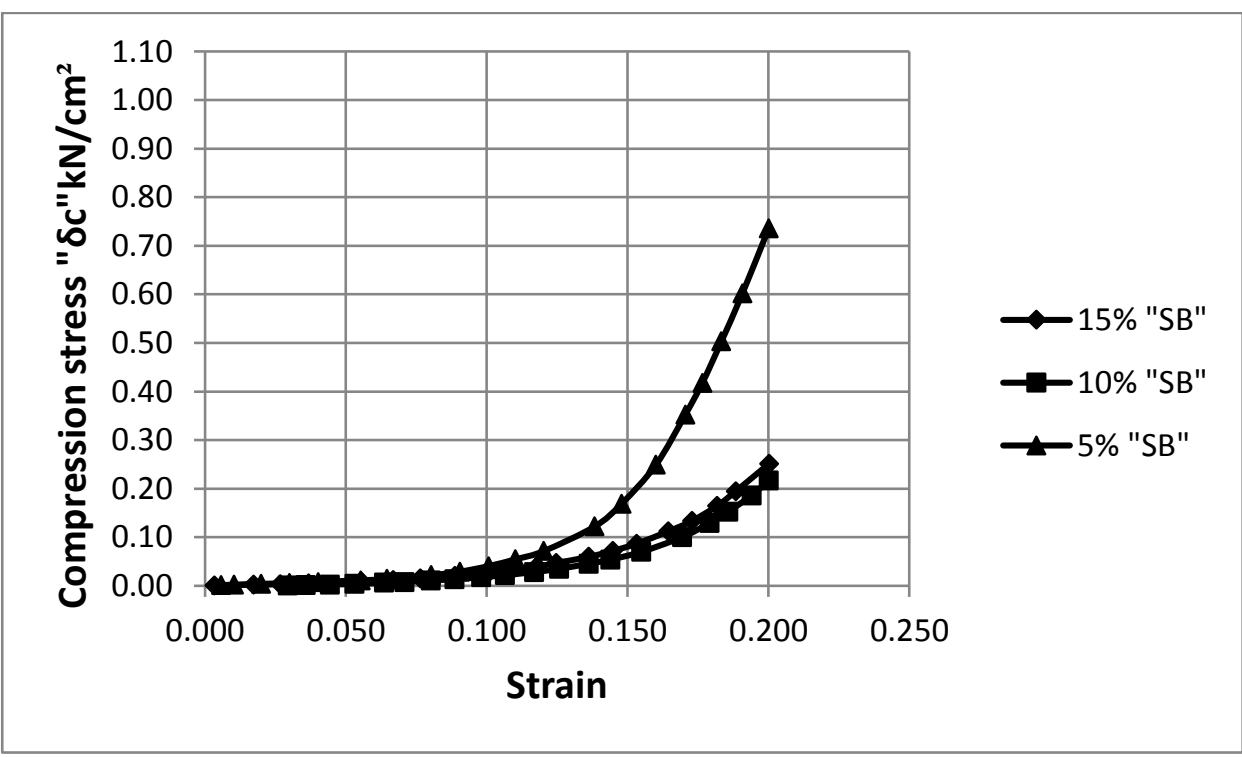

Fig. 11: Compression stress-strain curves of different bagasse percentage "SB" (\%) for large chops "LC". 


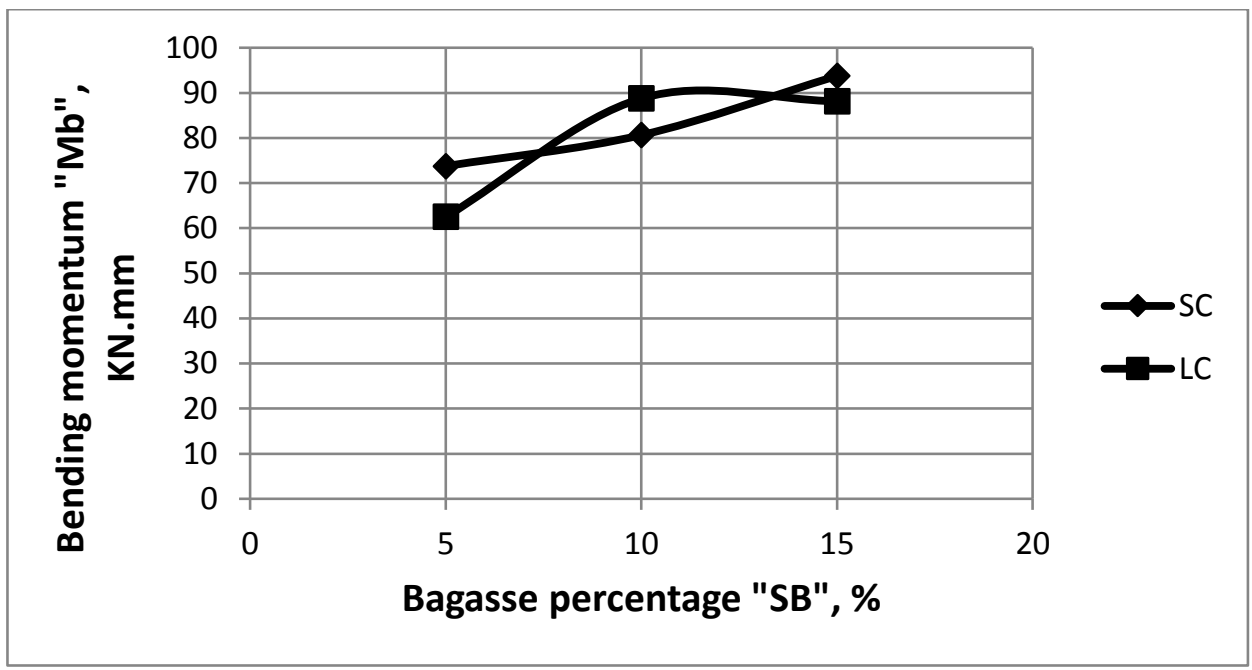

Fig. 12: Relation between bending momentum "Mb" (KN.mm) and bagasse percentage "SB" (\%) for "SC" and "LC".

\section{CONCLUSIONS}

Eco-friendly brick manufacturing has good specifications were investigated. Specimens prepared from six components, it half are wastes harmful on the health of human and causes environmental problems (CKD, SB and FA). Water used to mix the materials, then, pressing apparatus (calibrated hydraulic cylinder) used to press out the mixtures, with formation pressure about $45.98 \mathrm{Kg} / \mathrm{cm}^{2}$ for $30 \mathrm{~min}$. A serious measurement was conducted to determine physic-mechanical and functional brick properties. Results confirmed that the brick composite of: $59 \%$ wastes $(35 \% \mathrm{CKD}+15 \% \mathrm{SB}+9 \% \mathrm{FA})+21 \% \mathrm{OPC}+15 \% \mathrm{~S}+5 \%$ HL have good specifications and can be used to potential applications.

\section{REFERENCES}

Aggarwal L.K. (1995). Bagasse -Reinforced Cement Composites. Cement \& Concrete Composites. 17(1995) 107-112.

Algin H.M., P. Turgut (2008). Cotton and limestone powder wastes as brick material. Construction and Building materials 22(6): 10741080.

ASTM, C 67. (2001). Standard Test Methods for Sampling and Testing Brick and Structural Clay Tile. 
ASTM, C 109/C109 M. (1999). Standard Test Method for Compressive Strength of Hydraulic Cement Mortars.

ASTM, C 150. (2000). Standard Specification for Portland Cement 1. ASTM, C 642. (1997). Standard Test Method for Density, Absorption, and Voids in Hardened Concrete.

ASTM, C 778. (2000). Standard Specification for Standard Sand for use in the testing of hydraulic cements.

ASTM, C 911. (1999). Standard Specification for Quicklime, Hydrated Lime, and Limestone for Chemical Uses.

ASTM, C 1038. (1995). Standard Test method for Expansion of Portland Cement Mortar Bars Stored in Water.

Basta A.H.E.S. Abd El-Sayed and H. El-Saied (2004). Lignocellulosic materials in building elements. Part iv-economical manufacture and improvement of properties of light-weight agro-panel. International Journal of Polymeric Materials, 53(8): 709-723.

Claye, S. S., Idouraine, A., and Weber, C. W., (1996). Extraction and fractionation of insoluble fiber from five fiber sources. Food Chemistry, 57, 305-310.

ES 4756-1. (2013). Egyptian standard specification for cement number 1.

EN 197-1. (2000). Europian Normalisation, cement part: 1 composition, specifications and conformity criteria for common cements, Brussels Belgium.

IS. 456. (2000). Plain and Reinforced Concrete-Code of Practice [CED 2: Cement and Concrete.

Masuka S., Gwenziw., and T. Rukuni (2018). Development engineering properties and potential applications of unfired earth bricks reinforced by coal fly-ash, lime and wood aggregates. Journal of Building Engineering, Manuscript: 1-39.

Mohamed I. Abukhashaba, Mostafa A. Mostafa, Ihab A. Adam (2014). Behavior of self-compacting fiber reinforced concrete containing cement kiln dust. Alexandria Engineering Journal (2014) 53, 341-354.

Moussa, A. M. (2008). Effect of some adhesive matter on agricultural wastes as building materials. M. Sc., Thesis, Agric. Eng., Al-Azhar Univ. 
Singh, N. B., K. N. Bhattacharjee and A. K. Shukla (2000). Effect of alkali bypass dust on the hydration of granulated blast furnace slag blended cement. Department of Chemistry University of Gorakhpure, India. 25(4): 883-892.

Zhu, W. H., Tobis, B. C., Coutts, R. S. P. \& Langfors, G.(1994). Air cured banana-fiber reinforced cement composites. Cement \& Concrete Composites. 16(1994) 3-8.

$$
\begin{aligned}
& \text { الملخص العربي } \\
& \text { إستخدام مصاصة القصب مع تراب الأسمنت فى إنتاج الطوب المبي }
\end{aligned}
$$

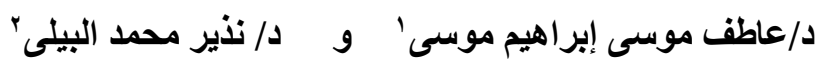

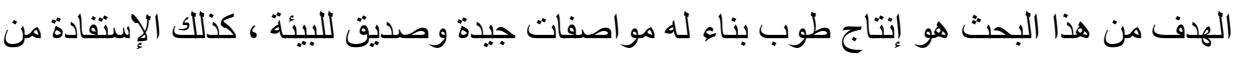

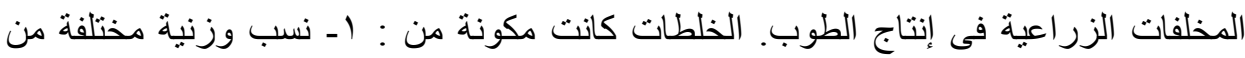

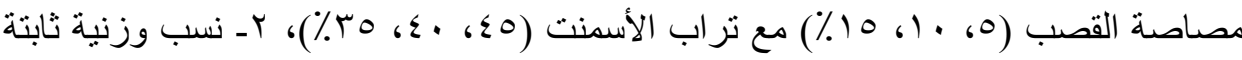

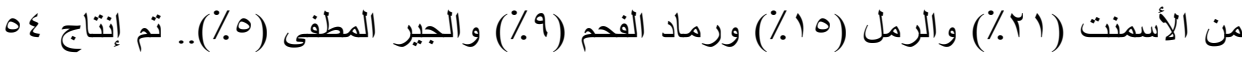

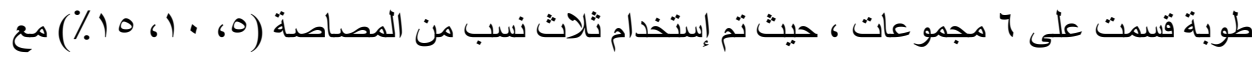

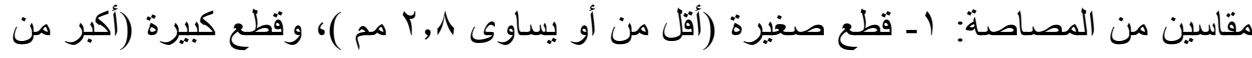

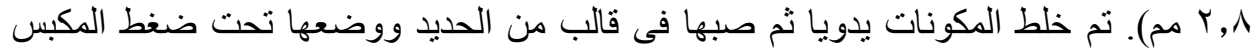

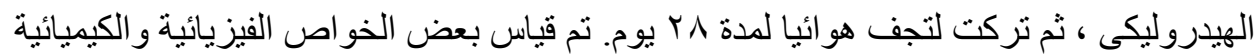

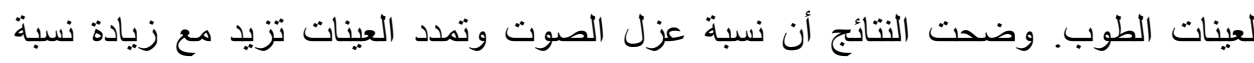

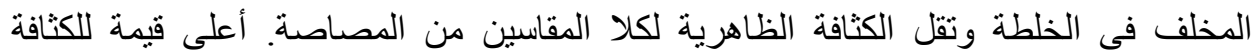

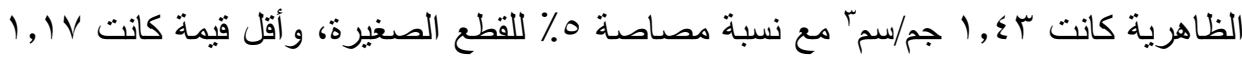

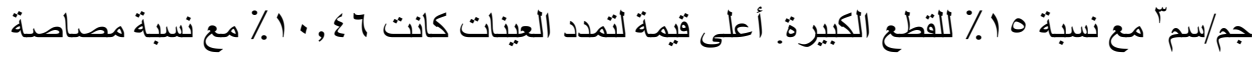

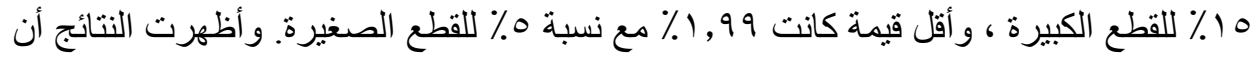

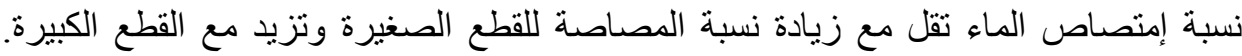

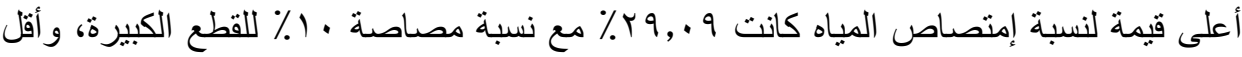

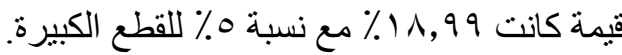

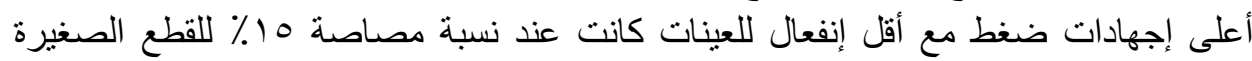

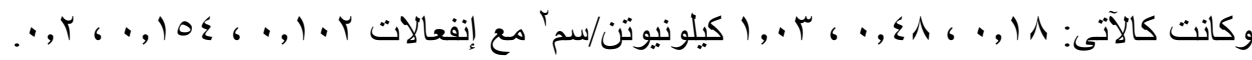

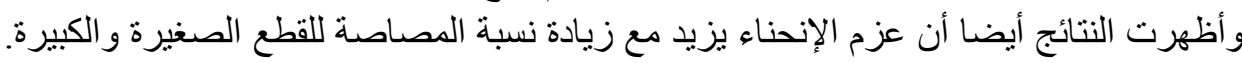

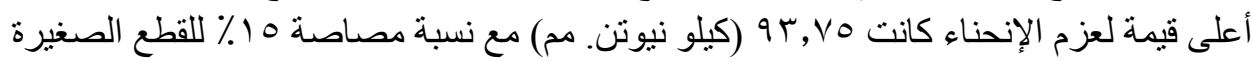

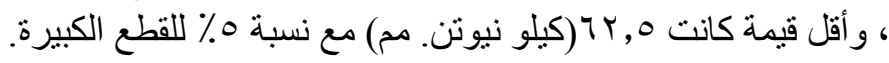

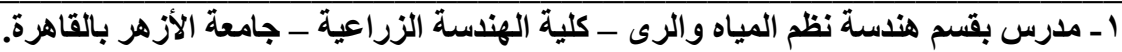
r ـ باحث مساعد ـ معهد بحوث الهندسة الزراعية ـ مركز البحوث الزراعية ـ الجيزة. 